\title{
Viewpoint
}

\section{Discussion of "Application of the Universal Soil Loss Equation to Rangelands on a Per-Storm Basis," by Trieste and Gifford in Journal of Range Management 33:66-70, 1980}

\author{
G.R. FOSTER, J.R. SIMANTON, K.G. RENARD, L.J. LANE, AND H.B. OSBORN
}

\section{Background}

Trieste and Gifford (1980) attempted to assess the applicability of the Universal Soil-Loss Equation (USLE) (Wischmeier and Smith 1965,1978 ) to rangelands on a per-storm basis and concluded that the USLE may give misleading rather than useful results where soil loss from rangeland is dominated by single storm events. We question their conclusion and suggest that the research approach they used to reach that conclusion was inappropriate. Their limited analysis of the USLE does not reflect how the rather extensive literature on the USLE, basic erosion mechanics, rainfall simulators, or the "state-of-the-art" of erosion prediction techniques relates to application of the USLE to rangeland. While most USLE literature is for cropland, basic USLE principles developed in that literature should have been given greater consideration by Trieste and Gifford. The principles from this literature should not be rejected simply because they were not developed from data collected on rangelands.

The USLE was originally derived from over 10,000 plot-years of data from natural rainfall on field plots longer than $11 \mathrm{~m}$; most plots were $22 \mathrm{~m}$ long, but some were as long as $192 \mathrm{~m}$ (Wischmeier and Smith 1965). More recently, these data have been supplemented by the equivalent of, perhaps, 1,000 plot-years of data from $11 \mathrm{~m}$ and $23-\mathrm{m}$-long field plots under simulated rainfall with energy near that of natural rainfall (Wischmeier and Smith 1978). The USLE was originally developed for cropland and has been extended to construction sites, strip mines, disturbed forests, and rangelands (Wischmeier and Smith 1978; Dissmeyer and Foster 1981; Osborn et al. 1977).

The USLE is perhaps the most thoroughly validated procedure in widespread practical use for estimating a hydrologic variable (erosion) over a wide range of conditions. Trieste and Gifford's statement that "validation studies are badly needed to verify annual predictions by the USLE" is not the case in general, especially for cropland (Wischmeier 1972).

The USDA-Soil Conservation Service (SCS) has been using the USLE since the early 1960's to estimate erosion on cropland and, more recently, on rangeland, surface mines, construction sites, and

Authors are hydraulic engineer, USDA-SEA-AR, Dept. of Agricultural Engineering, Purdue University, West Lafayette, Indiana; hydrologist, hydraulic engineer hydrologist, and hydraulic engineer, USDA-SEA-AR, Southwest Rangeland Watershed Research Center, Tucson, Arizona.

This article is a contribution from the USDA-Science and Education Administration-Agricultural Research. forestland. The USLE was extended to rangeland in 1972 (Wischmeier 1975) with parameter values developed from proven, fundamental concepts and data for the effect of canopy, ground cover, and undisturbed soil conditions on erosion. Although the general validity of these values was certain, it is true that they have not been validated with extensive rangeland plot data such as were available for cropland. Since experience with the USLE applied to rangeland has been brief, published parameter values (Wischmeier and Smith 1978) may not cover the full range of field conditions for rangelands. Improvement, refinement, and additional validation of values for several USLE parameters is desirable for application of the USLE specifically to rangelands and in the West in general. However, the present suggested USLE procedures can produce very useful results provided the user is cautious to avoid misuse. Examples of misuse of the USLE include applying the equation to situations outside the range of validity, such as very short slopes ( 5 $\mathrm{m}$ and shorter) and very long slopes (350 $\mathrm{m}$ and longer); using a parameter value for an undisturbed, smooth condition when the field situation is highly disturbed and rough; and use of the equation to estimate soil loss from a specific storm event (Wischmeier 1976).

Although Trieste and Gifford clearly state that their analysis applies to application of the USLE on a per-storm basis, their paper has implications on the general applicability of the USLE to rangeland. Therefore, we are presenting an alternate point of view to raise questions about Trieste and Gifford's research approach using small plots, which is different from the traditional approach of using plots at least $10 \mathrm{~m}$ long. Limited data from large plots and watersheds would be more useful than much data from small plots. Since Trieste and Gifford used a nontraditional approach of small plots for USLE factor evaluation, it is their responsibility to present a strong, conclusive, documented case with data that their results from small plots are comparable to those from longer plots that are traditionally used to study the USLE before they conclude that the USLE is so likely to mislead.

\section{Applicability of Small Plots}

Trieste and Gifford assumed that the USLE applied to their data, that is, to specific simulated rainstorms and small plots of 1 $\mathrm{m}^{2}$ and smaller. The validity of their analysis depends on the validity of this assumption which, unfortunately, they did not assess. We believe that their assumption is invalid. 
The USLE is intended to estimate soil loss on an average annual basis, not on a specific storm basis (Wischmeier 1976; Wischmeier and Smith 1978). However, if the USLE is applied to a specific storm that occurs many times over a long period on a varieity of antecedent conditions, the computed soil loss for the storm should be an accurate estimate of the average soil loss for many occurrences of the storm (Wischmeier and Smith 1978).

A variety of soil and moisture conditions may exist at the time of any particular storm. Erosion is usually less when a storm occurs on a dry soil than when it occurs on a wet soil. The probability of a storm occurring on a dry soil is generally greater than the probability of it occurring on a wet soil unless the climate is such that most of the rainfall occurs as a series of storms, preventing the soil from drying appreciably between storms (Wischmeier et al. 1971). About $60 \%$ of Trieste and Gifford's data (Busby 1977; Gifford and Busby 1974; Gifford et al. 1970; Williams et al. 1969) were biased toward wet conditions because the experimental procedure was to prewet the soil for 2 to 3 hours before collecting the erosion data.

The USLE reflects the natural distribution of rainfall events and antecedent conditions. The proper weighting of data from constant intensity rainfall simulators to reflect this natural distribution has not been determined. Other studies where rainfall simulators were used to develop USLE relationships included tests on both dry and wet antecedent moisture conditions (Wischmeier et al. 1971). Trieste and Gifford did not discuss how they considered this rather important factor in their use and analysis of rainfall simulator data related to USLE parameters such as the soil erodibility factor $\mathbf{K}$. Obviously, a factor value which represents a weighted average for a range of antecedent moisture conditions can give poor results if applied to an extreme of the range. by

Basic erosion mechanics suggest that erosion may be described

$$
A=C_{\mathrm{s}}+C_{\mathrm{r}} \boldsymbol{x}
$$

where $A$ is soil loss per unit area, $x$ is distance along the slope from the origin of overland flow, $C_{\mathrm{s}}$ is a constant for sheet erosion and $C_{\mathrm{r}}$ is a constant for rill erosion. The reader is referred to Foster et al. (1977), Foster and Meyer (1972), Foster and Meyer (1975), and Meyer et al. (1975a and b) for a complete discussion of the derivation and validation of this equation form. When slope length is zero, erosion occurs at the rate $C_{\mathbf{s}}$. The USLE, which lumps sheet and rill erosion and sediment transport by surface runoff together into a single component, gives zero erosion at zero slope length. The USLE, as an approximation of equation 1, has a range of limited validity for slope length. To illustrate, values were selected for $C_{\mathrm{s}}$ and $C_{\mathrm{r}}$ to fit equation 1 to the USLE and to give the USLE slope length exponent of 0.5 in the neighborhood of $22.1 \mathrm{~m}$. The fitting criterion is that sediment load from interrill (sheet) erosion equals that from rill erosion at $22.1 \mathrm{~m}$ (Foster et al. 1977; Meyer et al. 1975b). Values from the USLE and equation 1, plotted in Figure 1 , agree within $10 \%$ over the slope length range 6 to $83 \mathrm{~m}$. The effective slope length exponent of soil loss vs. slope length equals the slope of the lines in the log-log plot of Figure 1 (Foster and Meyer 1972; Foster et al. 1977). Note that the slope of the line for equation 1 is very flat at slope lengths less than $6 \mathrm{~m}$. Consequently, slope length exponents determined from plot lengths less than $3 \mathrm{~m}$ will be much too small for slope lengths $15 \mathrm{~m}$ and greater. This idea is supported very well by basic experimental data (Meyer et al. $1975 \mathrm{~b})$. The USLE can be expected to give poor results for slope lengths less than $6 \mathrm{~m}$ and certainly should not be applied to slopes 2 $m$ or less in length. Since the largest plot used by Trieste and Gifford was $1 . \mathrm{m}^{2}$, likely, all of their slope lengths were shorter than 2-3 m even if their plots were rectangular rather than square.

Plots as small as $1 \mathrm{~m}^{2}$, generally, cannot be used to develop USLE parameter values or to evaluate the USLE. Plots so small measure only sheet erosion, which Trieste and Gifford recognized, but the USLE estimates both sheet and rill erosion and transport by runoff. Such plots are too short for significant rill erosion to occur or for runoff to accumulate to influence sediment transport

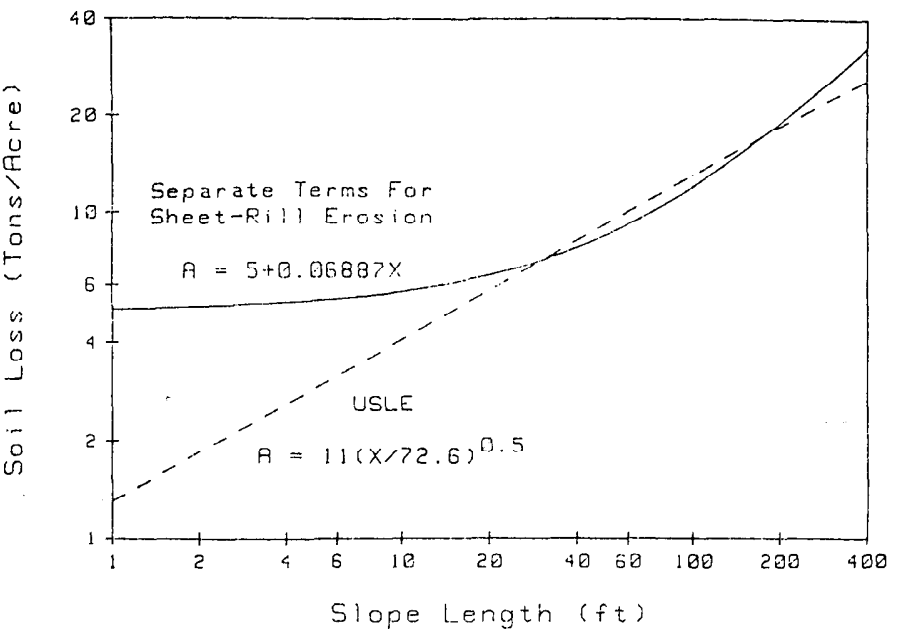

Fig. 1. Soil loss as a function of slope length as estimated by the USLE and as estimated by an equation having separate terms for sheet and rill erosion.

as it does on more common field slope lengths such as $50 \mathrm{~m}$. To illustrate, assume a steady runoff rate of $50 \mathrm{~mm} / \mathrm{hr}$ on a $6 \%$ slope and a Manning's $n$ of 0.015 for a bare soil (Lane et al. 1975). Average shear stress, which is frequently used as a measure of the erosivity of runoff, is $0.13 \mathrm{~N} / \mathrm{m}^{2}$ for a $1 \mathrm{~m}$ slope length, while it is $1.3 \mathrm{~N} / \mathrm{m}^{2}$ for a $50 \mathrm{~m}$ slope length. The critical shear stress of noncohesive, 100 micron diameter sand particles is about $0.7 \mathrm{~N} / \mathrm{m}^{2}$ (Graf 1971). This is significantly greater than the shear stress of runoff on the 3-ft slope length. Without the impacting raindrops to give the flow increased transport capacity, the flow at $1 \mathrm{~m}$ could not transport particles of this size. At $50 \mathrm{~m}$ the shear stress of the flow alone, without input from the rain drops, can transport this size of particle, because the shear stress of the flow exceeds the critical values for transport. The importance of various erosion processes depends on location along the slope. At the slope's upper end, the effect of impacting raindrops is usually dominant, while the effect of flow may be dominant on the lower end of a long slope, especially if rill erosion or deposition in local depressions is occurring.

Thus, the relative importance of sheet and rill erosion and sediment transport capacity of runoff depends on characteristics of rainfall and runoff, soil, slope length and steepness, cover and management, as shown theoretically by Foster er al. (1977) and expcrimentally by Meyer et al. (1975b).

The claim might be made that small plots are a relative measure of erosion even though they may not be an absolute measure of the erosion estimated by the USLE. That claim, too, is questionable. Plots as small as $1 \mathrm{~m}^{2}$ measure primarily $C_{\mathrm{s}}$ of equation 1 and not $C_{\mathrm{r}}$, while the USLE is an aggreate measure of both $C_{\mathrm{s}}$ and $C_{\mathrm{r}}$. The assumption that $C_{\mathrm{s}}$ and $C_{\mathrm{r}}$ would show and as experimental evidence has shown. Meyer et al. (1975b) found that although sheet erosion from two $10.7 \mathrm{~m}$ long plots was essentially equal, total erosion was greatly different because rill erosion on the two plots was greatly different. In addition, a particular erosion control practice could be quite effective on a short plot because it greatly reduced soil detachment by raindrop impact but was ineffective on a long plot where rill erosion and sediment transport by accumulated overland flow is important (Meyer et al. 1975b). Consequently, neither absolute nor relative values from small plots can, in general, be reliably applied to the USLE.

Erosion can be extremely variable from point to point. A single shrub, depression, gopher hole, or ridge in a small plot may totally dominate soil loss from the plot. Large plots dampen the influence of heterogeneities in the controlling factors while including several more erosion-sediment transport processes that operate on typical slopes and which are included in the USLE. Perhaps, the USLE represents natural conditions of erosion and sediment transport on common slope lengths better than the data used by Trieste and 


\section{Gifford.}

We recognize the value of small plots because of their convenience, cost savings, and their ability to stratify variance. Also, they are required to study soil detachment by raindrop impact. Yet, in spite of their advantages for erosion and other types of range studies, we cannot accept them as conclusive either in support of or against the USLE.

\section{Definitions}

The term sediment yield is applied by Trieste and Gifford to soil loss from small plots. Sediment yield is commonly defined as the eroded soil transported to some point in a stream. It includes sediment from sheet, rill, gully, and channel erosion. Deposition may cause sediment yield to be less than the total of sheet and rill erosion by the USLE. In other cases, channel erosion may increase sediment yield to greater than sheet and rill erosion. The USLE does not estimate sediment yield; neither are Trieste and Gifford's data a measure of sediment yield.

\section{Rainfall Erosivity (R) Factor}

Rainfall intensity during a storm generally varies and is not constant as it was in some, if not most, if the rainfall simulator tests of Trieste and Gifford. The erosivity factor, EI-product of a storm's total energy, E, and maximum 30-min intensity, I,- -was empirically derived from natural rainfall data (Wischmeier and Smith 1978). Therefore, the EI parameter could work well for variable intensity natural storms but not for constant intensity simulated storms if the simulated rainfall does not reproduce the important properties of natural rainfall. Failure of a parameter for simulated storms of constant intensity does not necessarily mean that it would fail for natural rainfall. The need for simulating variable intensity storms to develop erosion parameters for natural rainfall has not been explored in detail. Most erosion studies using simulated rainfall use constant rainfall intensity without assessing the validity of constant intensity. Mutchler and McGregor (1979) and Bubenzer (1979) discuss important characteristics for rainfall simulators in erosion research.

Trieste and Gifford's equation for total kinetic energy $E$ of a rainstorm is unclear. We assume that it should be:

$$
E=\sum_{\mathrm{i}=1}^{\mathrm{n}}\left(916+331 \log _{10} X_{\mathrm{i}}\right)\left(X_{\mathrm{i}} * T_{\mathrm{i}}\right)
$$

where $X_{\mathrm{i}}$ and $T_{\mathrm{i}}$ equal, respectively, intensity and depth of rainfall for the ith increment of rain. Equation 2 is in U.S. customary English units. A value of about $2.8 \mathrm{~mm}$ (Bubenzer, 1979) seems better for mean drop diameter for natural rainfall rather than the $3.7 \mathrm{~mm}$ which Trieste and Gifford assumed. A 3.7 drop diameter is about the $d_{90}$ size $\left(90 \%\right.$ of the total volume is a size less than $d_{90}$ ) for natural rainfall at a $50 \mathrm{~mm} / \mathrm{hr}$ intensity.

To compute energy for the simulated storms, Trieste and Gifford used the equation.

$$
Y=916+331 \log _{10} X
$$

where $Y=$ unit kinetic energy (energy per unit area per unit of rainfall) at rainfall intensity $X$. This equation was derived from drop-size distributions and impact velocitics measured for natural rainfall (Wischmeier and Smith 1978), and neither it nor equation 2 apply to simulated rainfall. Since Trieste and Gifford had data for their rainfall simulators, there was no reason to use either equation 2 or 3 . To compute energy for a simulator requires computation of the energy of the drops of the various size classes that make up the simulator's drop distribution:

$$
\left.E=\sum_{\mathrm{i}=1}^{\mathrm{n}} m_{\mathrm{i}} V_{\mathrm{i}}^{2}\right) / 2
$$

where $m_{\mathrm{i}}=$ mass of water falling at velocity $V_{\mathrm{i}}$. The index $i$ is for the drop-size classes making up the distribution. Energy should not be computed by representing the entire drop distribution by the median drop size because the relationships are nonlinear. That is, the velocity of the median drop is not the same as the "velocity of the rainfall," as assumed by Trieste and Gifford. One half of the total kinetic energy for natural rainfall is produced by drops larger than the $\mathrm{d}_{70}$ diameter (E.L. Neff, May, 1980, USDA-SEA, Sidney, Montana, personal correspondence). Their adjustment to account for lesser energy from their rainfall simulators compared with natural rainfall contains errors which may have influenced their results.

Including other factors such as runoff in the USLE erosivity factor potentially would improve soil loss estimates. Even though $\mathrm{EI}$ is a rainfall term, runoff volume and peak rate are correlated with EI because of runoff's relation to rainfall intensity and volume. Therefore, runoff effects are considered by the USLE. Lombardi (1979) found that for 25 bare fallow plots at 11 locations with a total of 2,586 soil loss producing storms, an average of 103 storms per plot, EI explained, on the average, $60.4 \%$ of the variation in soil loss. Including runoff in the erosivity factor and analyzing the data according to the latest erosion theory improved the average $R^{2}$ to $72.7 \%$. The runoff volumes used were measured values. If they had been estimated, as would be necessary in an applied equation, $R^{2}$ would probably have been close to $60 \%$. However, Lombardi (1979) noted a better correlation between soil loss and a product of runoff volume and an estimate of peak runoff rate than between soil loss and EI. Williams (1975) also found a better correlation of sediment yield with a similar product than with EI. It could be concluded that runoff is an important erosivity factor, emphasizing again the need for long plots.

\section{Soil Erodibility (K) Factor}

We are not surprised that Trieste and Gifford did not find a correlation of erosion on small plots with the soil erodibility factor $\mathrm{K}$, particularly if $\mathbf{K}$ did not vary over a wide range. W.C. Moldenhauer (Soil Scientist, USDA-SEA-AR, Lafayette, Indiana, personal communication) found, after extensive testing with simulated rainfall on small plots of midwestern agricultural soils, that $\mathrm{K}$ factors determined from small plots often will not even rank in the same order as $\mathbf{K}$ from USLE plots. Important runoff processes related to detachment and transport mechanisms that play a major role on large plots do not operate on small plots.

\section{Slope Length (L) Factor}

Trieste and Gifford found that soil loss was negatively correlated with the $\mathrm{L}$ factor, yet in their power equation they show $\mathrm{L}^{0.99}$. They also stated that erosion decreased with an increase in slope length for their data, which would require a negative exponent. Either their statement or their equation is incorrect. If their negative exponent is correct, soil loss from a $30 \mathrm{~m}$ long slope would be 0.1 times that from $0.3 \mathrm{~m}$ slope length according to their equation. This result, if actually found by Trieste and Gifford, is unacceptable, because it contradicts both erosion theory and data from plots on agricultural soils.

Erosion on small plots is not a function of slope length when detachment by raindrop impact is the dominant erosion process. Erosion from raindrop impact is essentially constant over a plot having a uniform slope, soil, and cover (Meyer et al. 1975b, Foster et al. 1977). The slope length effect in an erosion equation like the USLE is from rill erosion, which hardly occurs on small plots. Furthermore, use of $1 \mathrm{~m}^{2}$ and smaller plots to comment on the effect of slope length on erosion on areas where slope lengths reach $150 \mathrm{~m}$ is clearly questionable. Such small plots cannot be used to evaluate LS factors for the USLE.

Trieste and Gifford stated, "However, the slope length factor $(\mathrm{L})$ was originally derived from data collected from plots of a fixed length ( $72.6 \mathrm{ft}$ ) and then extrapolated to slopes of different lengths.

"This statement is incorrect. The $\mathrm{L}$ factor was determined from data from 15 studies in 9 states (Wischmeier et al. 1958). Maximum plot lengths in two of the studies were 82 and $192 \mathrm{~m}$. In the other studics, the maximum was $44 \mathrm{~m}$. Most of the slope lengths were 11 , 22.1 , and $44 \mathrm{~m}$. Slope steepness ranged from 3 to $18 \%$ for these studies. 


\section{Slope Steepness (S) Factor}

Erosion on small plots does not increase as rapidly with increasing slope steepness as does the USLE S factor (Meyer et al. 1975b). Therefore, Trieste and Gifford's $\mathrm{S}^{0.49}$ is reasonable for small plots, but not for the USLE. Rill erosion, hardly present on small plots, is strongly related to slope steepness (Foster et al. 1977).

\section{Cover-Management (C) Factor}

Trieste and Gifford's power equation with a negative exponent for $\mathbf{C}$ suggests that as $\mathbf{C}$ decreases, erosion increases. If their data were highly scattered, and if $\mathrm{C}$ covered a narrow range, this result could occur. Perhaps Trieste and Gifford did not consider several important factors as they selected $\mathbf{C}$ values. Since their source for $\mathbf{C}$ values is not listed as a literature citation, and since detailed descriptions of surface conditions for their plot data are not readily available, we cannot assess the validity of their $C$ factor values. Trieste and Gifford mention that soil cover characteristics do not adequately reflect the hydrologic performance of big sagebrush cover which has been grossly modified by activity such as root plowing or grazing. Scientists studying erosion in agricultural situations have long recognized that other factors besides cover, like roughness, tillage soil disturbance, and previous management, affect erosion (Foster and Meyer 1977, Wischmeier 1973, Wischmeier and Smith 1978). A recent article by Dissmeyer and Foster (1981) provides additional factor values that can be used for rangeland that has been root plowed. The plant classification by Wischmeier and Smith (1978) and by Dissmeyer and Foster (1981) may be ecologically unorthodox, but the classification was based on plant and soil characteristics having significant effect on erosion. For example, percent of ground and canopy cover is usually more important than weight of the standing ground cover.

In studies where component factors like canopy, ground cover, and roughness have been separately evaluated (Wischmeier and Smith 1978; Wischmeier, 1973; Dissmeyer and Foster 1980), ground cover was the single greatest important factor when the full range of possible conditions was considered. A small $\mathrm{C}$ factor for rangeland is about 0.003 for a $95 \%$ cover of grass (Wischmeier and Smith 1978). A large $C$ factor is 1.0 for periodically tilled bare soil. Substitution of these values into Trieste and Gifford's power equation (page 70) from soil loss with the negative exponent for $\mathrm{C}$ suggests that soil loss from the grass is 1.34 times that from the bare soil. The USLE will predict that the grass is only 0.003 times as erodible as the bare soil. From experience, we know that the soil beneath grass is less erodible than bare soil rather than the reverse, as Trieste and Gifford's equation suggests.

\section{General Comments}

Trieste and Gifford state that:

The equation on a per-storm basis could not account for the variation in sediment yields as a function of soil condition, plant communities, antecedent moisture conditions, or season. . . The factors in the USLE, as presently defined, evidently do not constitute the important parameters that explain soil loss in wildland conditions on a per-storm basis, or else optimizing those factors with exponents would seemingly have accounted for the variability involved. . . Where sediment yields are dominated by single storm events, application of the equation to rangeland situations may be misleading rather than useful.

We disagree with Trieste and Gifford's conclusions and believe that their analysis provided no basis for these conclusions. The USLE is indeed useful and it does reflect erosion as a function of the important variables, as Osborn et al. (1977) demonstrated on small watersheds in Southern Arizona. The conclusions reached by Trieste and Gifford may apply more to the use of small plots and simulated rainfall to study erosion on rangeland than to the applicability of the USLE to rangeland.

We by no means claim that the USLE is free of difficulty. In fact, research is needed under rangeland conditions to evaluate $K, C$, and $\mathbf{P}$ (supporting practices) factors and the effect of the highly variable $\mathbf{R}$ factor in the West. However, small plots are limited in the information they provide, although rainfall simulators and small plots are important tools in erosion research. They provide valuable information on erosion by raindrop impact, and are necessary for separating the effects of erosion by raindrop impact from those of rill erosion. There is the danger, however, of extrapolating small plot measurements to situations beyond their applicability, such as evaluating or developing USLE parameters.

\section{Literature Cited}

Bubenzer, G.D. 1979. Rainfall characteristics important for simulation. In: Proc. Rainfall Simulator Workshop, Tucson, Ariz. USDA-Sci. and Educ. Admin., ARM-W-10:22-27.

Busby, F.E. 1977. Effect of livestock grazing on infiltration and erosion rates measured on grazed and ungrazed pinyon-juniper sites in southeastern Utah. PhD Thesis, Utah State Univ., Logan, Utah. 130 p.

Dissmeyer, G.E., and G.R. Foster. 1981. The USLE cover-management factor (C) for forest conditions. (In Press) J. Soil and Water Conservation.)

Foster, G.R., and L.D. Meyer. 1972. A closed-form erosion equation for upland areas. In: Sedimentation (Einstein). H.W. Shen (ed.). Colorado State Univ., Fort Collins. Chapter 12.

Foster, G.R., and L.D. Meyer. 1975. Mathematical simulation of upland erosion by fundamental erosion mechanics. In: Present and Propsective Technology for Predicting Sediment Yields and Sources. USDA-Sci. and Educ. Admin. ARS-S-40. 190-207.

Foster, G.R., and L.D. Meyer. 1977. Soil erosion and sedimentation by water-An overview. Proc. National Symposium on Soil Erosion and Sedimentation by Water. ASAE Publication 4-77, Amer. Soc. of Agr. Eng., St. Joseph, Mich. p. 1-13.

Foster, G.R., L.D. Meyer, and C.A. Onstad. 1977. An erosion equation derived from basic erosion principles. Trans. Amer. Soc. Agr. Eng. 20:678-682.

Gifford, G.F., and F.E. Busby. 1974. Intensive infiltrometer studies on a plowed big sagebrush site. J. Hydrology 21:81-90.

Gifford, G.F., G. Williams, and G.B. Colthorp. 1970. Infiltration and erosion studies on pinyon-juniper conversion sites in southern Utah. J. Range Manage. 23:402-406.

Graf, W.H. 1971. Hydraulics of Sediment Transport. McGraw-Hill Book Co., New York. 544 p.

Lane, L.J., D.A. Woolhiser, and V. Yevjevich. 1975. Influence of simplification in watershed geometry in simulation of surface runoff. Hydrology Paper No. 81. Colorado State Univ., Fort Collins. 50 p.

Lombardi, F. 1979. Universal Soil Loss Equation (USLE), runoff erosivity factor, slope length exponent, and slope steepness exponent for individual storms. PhD Thesis, Purdue University, W. Lafayette, Ind. 128 p.

Meyer, L.D., G.R. Foster, and S. Nikolov. 1975a. Effect of flow rate and canopy on rill erosion. Trans. Amer. Soc. Agr. Eng. 18:905-911.

Meyer, L.D., M.J.M. Romkens, and G.R. Foster, 1975b. Source of soil eroded by water from upland slopes. In: Present and Prospective Technology for Predicting Sediment Yields and Sources. USDA-Science and Education Administration. ARS-S-40:177-189.

Mutchler, C.K., and K.C. McGregor. 1979. Geographical differences in rainfall. In: Proc. Rainfall Simulator Workshop, Tucson, Arizona. USDA-Sci. and Educ. Admin., ARM-W-10:8-16.

Osborn, H.G., J.R. Simanton, and K.G. Renard. 1977. Use of the universal soil loss equation in the semiarid Southwest. In: Soil Erosion: Prediction and Control. Special Pub. 21, Soil Conserv. Soc. Amer. p. 41-49.

Trieste, D.J., and G.F. Gifford. 1980. Application of the Universal Soil Loss Equation to rangelands on a per-storm basis. J. Range Manage. 33:66-70

Williams, J.R. 1975. Sediment-yield prediction with universal equation using runoff energy factor. In: Present and Prospective Technology for Predicting Sediment Yields and Sources. USDA-Sci. and Educ. Admin. ARS-S-40. p. 244-252.

Williams, G., G.F. Gifford, and G.B. Colthorp. 1969. Infiltrometer studies on treated vs. untreated pinyon-juniper sites in central Utah. J. Range Manage. 22:110-114.

Wischmeier, W.H. 1972. Upslope erosion analysis. In: Environmental Impact on Rivers. H.W. Shen, publisher. Colorado State Univ., Fort Collins. Chapter 15.

Wischmeier, W.H. 1973. Conservation tillage to control water erosion. Proc. National Conservation Tillage Conference, Soil Conserv. Soc. of Amer., Ankeny, Iowa. p. 133-141.

Wischmeier, W.H. 1975. Estimating the soil loss equation's cover and management factor for undisturbed areas. In: Present and Prospective Technology for Predicting Sediment Yields and Sources. USDA-Sci. and Educ. Admin. ARS-S-40:118-124. 
Wischmeier, W.H. 1976. Use and misuse of the universal soil loss equation. J. of Soil and Water Conserv. 31:5-9.

Wischmeier, W.H., C.B., Johnson, and B.V. Cross. 1971. A soil erodibility nomograph for farmland and construction sites. J. of Soil and Water Conserv. 26:189-193.

Wischmeier, W.H., and D.D. Smith. 1965. Predicting rainfall-erosion losses from cropland east of the Rocky Mountains-Guide for selection of practices for soil and water conservation. USDA-Agr. Handbk. No. 282.

Wischmeier, W.H., and D.D. Smith. 1978. Predicting rainfall erosion losses-A guide to conservation planning. USDA-Agr. Handb. No. 537. Wischmeier, W.H., D.D. Smith, R.E. Uhland. 1958. Evaluation of factors in the soil loss equation. Agr. Eng. 39:458-462. 474. 